\title{
$\beta$ Pix is a new player in renal physiology
}

\section{Kirk L. Hamilton ${ }^{1 *}$ and Alan C. Pao ${ }^{2}$}

1 Department of Physiology, Otago School of Medical Sciences, University of Otago, Dunedin, New Zealand

2 Division of Nephrology, Department of Medicine, Stanford University, Stanford, CA, USA

*Correspondence: kirk.hamilton@otago.ac.nz

Edited by:

Nuria M. Pastor-Soler, University of Pittsburgh School of Medicine, USA

Reviewed by:

Kenneth R. Hallows, University of Pittsburgh School of Medicine, USA

\section{A commentary on}

\section{Role of $\beta$ Pix in the kidney}

by Staruschenko, A., and Sorokin, A. (2012). Front. Physiol. 3:154. doi: 10.3389/ fphys.2012.00154

Small G proteins (small GTP-binding proteins; GTPases) are low molecular weight proteins that play major regulatory roles in numerous biological pathways including signal transduction, regulation of cellular polarity, actin and microtubule dynamics, gene transcription, cell cycle progression, and vascular transport pathways (Etienne-Manneville and Hall, 2002). Rho GTPases are one of the group of GTPases, which include RhoA, Rac1, and Cdc42 (Etienne-Manneville and Hall, 2002; Ory and Gasman, 2011). These small monomeric GTPases serve as molecular switches by cycling between an "active state" (bound to GTP) and an "inactive state" (bound to GDP) and by hydrolyzing GTP to GDP (Etienne-Manneville and Hall, 2002; Ory and Gasman, 2011). Guanine nucleotide exchange factors (GEFs) are responsible for the recruitment and activation of Rho GTPases at the cell membrane, whereas GTPase activating proteins (GAPs) inactivate the Rho GTPases (Ory and Gasman, 2011).

The focus of this Commentary is to highlight the recent review article by Staruschenko and Sorokin (2012) published in Frontiers of Physiology in which they have provided a brief background of the GEF $\beta$ Pix, but more importantly, they have reviewed the recent and very exciting roles of $\beta$ Pix in kidney physiology. $\beta$ Pix [p21-activated kinase (PAK)-interacting exchange factor $\beta$ ] is a GEF that modulates Rac1 and Cdc42 (Guilluy et al., 2011). As far as we can determine, there has only been a handful of reviews that address the biology and function of $\beta$ Pix and the related GEF $\alpha$ Pix (Bagrodia and Cerione, 1999; Rosenberger and Kutsche, 2006; Frank and Hansen, 2008; Schlenker and Rittinger, 2009; Momboisse et al., 2010).

For those readers unfamiliar with $\beta$-Pix (ARHGEF 7), this protein has had a number of previous names including COOL1, KIAA0142, P50BP, P85, P85SPR, PAK3, and PixB (HUGO Gene Nomenclature Committee; http://www.genenames.org/ data/hgnc_data.php?hgnc_id=15607). Oh et al. (1997) originally demonstrated that p85SPR [Src Homology 3 (SH3) domain containing proline-rich protein], now known as $\beta$ Pix, interacted with areas of focal adhesion, suggesting a role for $\beta$ Pix in cytoskeletal function. Shortly thereafter, Manser et al. (1998) reported the binding of $\beta$ Pix (and $\alpha$ Pix) to PAK1. Further, Bagrodia et al. (1998) identified ßPix (named p85Cool-1) and a smaller alterative splice variant (p50Cool-1) as two proteins that facilitated interactions between PAK and DBL homology (DH) and pleckstrin homology $(\mathrm{PH})$ domains. Finally, Koh et al. (2001) reported an isoform of $\beta$ Pix designated $\beta_{2}$ Pix; that isoform contained a serine-rich region not found in the original $\beta$ Pix protein (which is now designated as $\beta_{1}$ Pix-a, Kim et al., 2000) nor the $\beta_{1}$ Pix-b and $\beta_{1}$ Pix-c isoforms (Oh et al., 1997; Kim et al., 2000). The structure and functional domains of $\beta_{1}$ Pix are provided in Figure 1 .

There are a number of functions of $\beta_{1}$-Pix. Staruschenko and Sorokin (2012) describe that $\beta_{1}$ Pix participates in both canonical and non-canonical signaling pathways involved in various cellular functions (see Figure 1). The canonical signaling of $\beta_{1}$ Pix results from its GEF activity, which activates Rac1 and Cdc42, and regulates various cellular functions including cytoskeletal reorganization, morphogenesis, and cell migration (Figure 1). $\beta_{1}$ Pix also exhibits non-canonical activities in which it serves as a scaffolding protein in some signaling pathways (Pavlov et al., 2010).

Staruschenko and Sorokin (2012) also provide an overview of the expression of $\beta$ Pix in the kidney and the various roles of $\beta$ Pix in kidney function. Recently, $\beta$ Pix expression has been detected in mesangial cells, podocytes, cortical collecting ducts, and localized vessels and vascular smooth muscle cells of the rat kidney and in a number of nephron segment-specific derived cell lines (antibodies against $\beta$ Pix were unable to discriminate between the $\beta_{1}$ Pix and $\beta_{2}$ Pix isoforms, Pavlov et al., 2010). These findings set the stage for unraveling the roles of $\beta$ Pix in renal physiology, which is presented under four categories (Staruschenko and Sorokin, 2012): (i) regulation of ion transport, (ii) regulation of glomerular function, (iii) regulation of urothelial signaling, and (iv) complexity of $\beta$ Pix signaling in the kidney.

One of the most exciting advances in our understanding of $\beta_{1}$ Pix function in the kidney involves the role of $\beta_{1}$ Pix in regulating the epithelial sodium channel $(\mathrm{ENaC})$ in the cortical collecting duct. Staruschenko and colleagues (Pavlov et al., 2010) have recently demonstrated that endothelin-1 signals through $\beta_{1}$ Pix to decrease the number of $\mathrm{ENaC}$ channels in the apical cell membrane of cortical collecting duct cells. $\beta_{1}$ Pix negatively regulates $\mathrm{ENaC}$ by binding to 14-3-3 proteins and disrupting the interaction between 14-3-3 proteins and the E3 ubiquitin ligase Nedd4-2. A major regulator of $\mathrm{ENaC}$, Nedd4-2 ubiquitinates cell surface $\mathrm{ENaC}$, marking the channel for internalization and degradation. Since 14-3-3 proteins inhibit Nedd4-2 activity, $\beta_{1}$ Pix blocks 14-3-3 proteins from interacting and inhibiting 


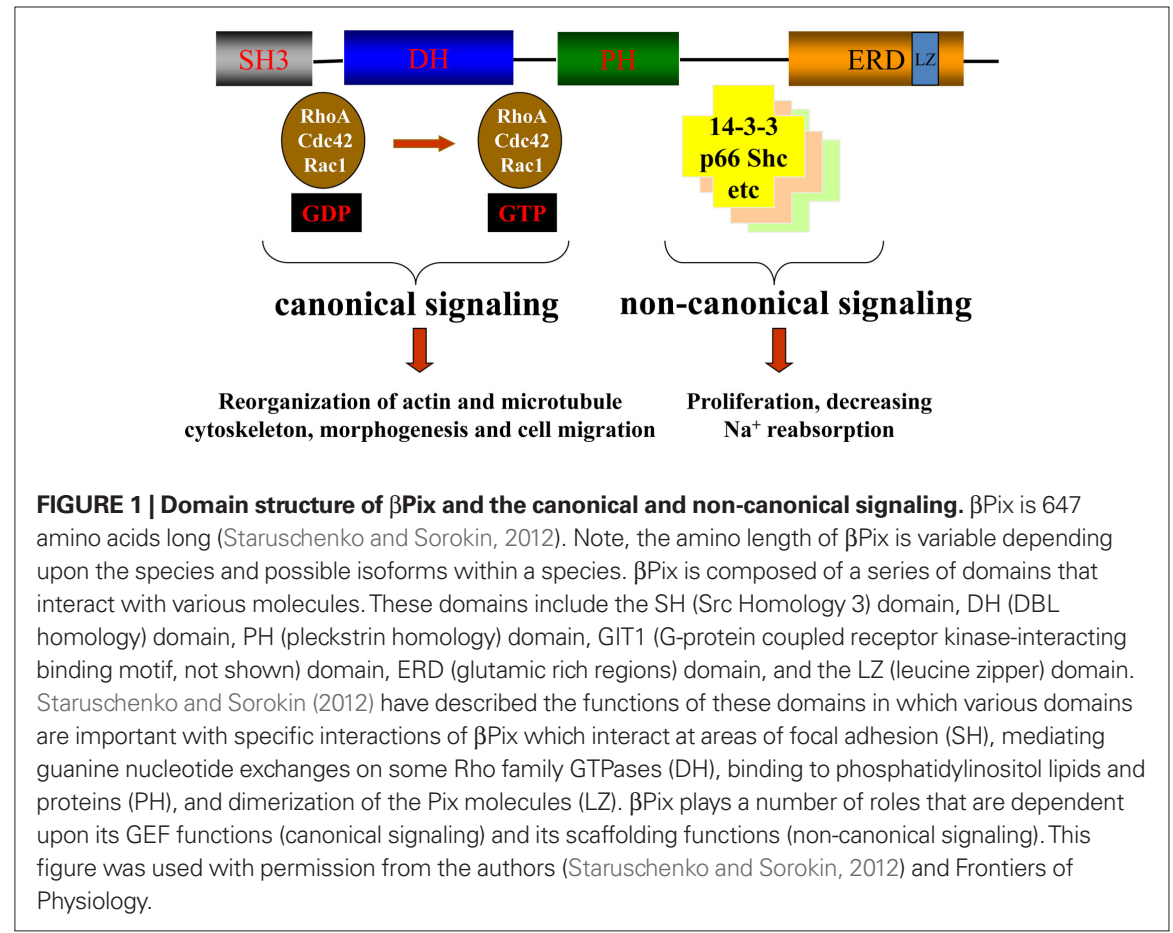

Nedd4-2, thereby enabling Nedd4-2 to inhibit $\mathrm{ENaC}$. Interestingly, this inhibitory effect is dependent on the role of $\beta_{1} \mathrm{Pix}$ as a scaffold protein rather than a GEF.

To date, there have been no reports of any mouse models or human diseases that are associated with $\beta$ Pix deficiency or dysfunction. There are, however, studies that implicate $\beta$ Pix over-expression in human breast cancer tissue, suggesting that $\beta \mathrm{Pix}$ plays a significant role in controlling cell proliferation and carcinogenesis and may be a potential marker of malignant disease (Ahn et al., 2003). In future studies, the relative contribution of various $\beta$ Pix functions in the kidney will need to be confirmed in vivo.

\section{FINAL THOUGHTS}

The review paper by Staruschenko and Sorokin (2012) is very timely as the role of $\beta$ Pix in a number of tissues is still emerging, especially within the kidney. Certainly as $\beta$ Pix knock-out mice models are generated, additional new and exciting role(s) of $\beta$ Pix will be clearly demonstrated.
Additionally, experiments that isolate the canonical and non-canonical pathways by which $\beta$ Pix operates will define very specific functions of $\beta$ Pix within the kidney and possibly lead to the development of novel treatment strategies for renal disease.

\section{ACKNOWLEDGMENTS}

We thank Dr. Ed Manser for discussions about $\beta$ Pix and PAKs. We also thank Frontiers in Physiology and Drs. Staruschenko and Sorokin for the use of Figure 3 from their original paper. This work was supported by the Department of Physiology, University of Otago and the Department of Medicine, Stanford University.

\section{REFERENCES}

Ahn, S. J., Chung, K. W., Lee, R. A., Park, I. A., Lee, S. H., Park, D. E., and Noh, D. Y. (2003). Overexpression of $\beta$ Pix-a in human breast cancer tissues. Cancer Lett. 193, 99-107.

Bagrodia, S., and Cerione, R. A. (1999). Pak to the future. Trends Cell Biol. 9, 350-355.

Bagrodia, S., Taylor, S. J., Jordon, K. A., Van Aelst, L., and Cerione, R. A. (1998). A novel regulator of p21-activated kinases. J. Biol. Chem. 273, 23633-23636.
Etienne-Manneville, S., and Hall,A. (2002). Rho GTPases in cell biology. Nature 420, 629-635.

Frank, S. R., and Hansen, S. H. (2008). The PIX-GIT complex: a $G$ protein signaling cassette in control of cell shape. Semin. Cell Dev. Biol. 19, 234-244.

Guilluy, C., Garcia-Mata, R., and Burridge, K. (2011). Rho protein crosstalk: another social network? Trends Cell Biol. 21, 718-726.

Kim, S., Kim, T., Lee, D., Park, S. H., Kim, H., and Park, D. (2000). Molecular cloning of neuronally expressed mouse $\beta 1$ Pix isoforms. Biochem. Biophys. Res. Commun. 272, 721-725.

Koh, C. G., Manser, E., Zhao, Z. S., Ng, C. P., and Lim, L. (2001). $\beta 1$ Pix, the PAK-interacting exchange factor, requires localization via a coiled-coil region to promote microvillus-like structures and membrane ruffles. J. Cell Sci. 114, 4239-4251.

Manser, E., Loo, T. H., Koh, C. G., Zhao, Z. S., Chen, X. Q., Tan, L., Tan, I., Leung, T., and Lim, L. (1998). PAK kinases are directly coupled to the PIX family of nucleotide exchange factors. Mol. Cell 1, 183-192.

Momboisse, F., Ory, S., Ceridono, M., Calco, V., Vitale, N., Bader, M. F., and Gasman, S. (2010). The Rho guanine nucleotide exchange factors Intersectin $1 \mathrm{~L}$ and $\beta-P i x$ control calcium-regulated exocytosis in neuroendocrine PC12 cells. Cell. Mol. Neurobiol. 30, 1327-1333.

Oh, W. K., Yoo, J. C., Jo, D., Song, Y. H., Kim, M. G., and Park, D. (1997). Cloning of a SH3 domain-containing proline-rich protein, p85SPR, and its localization in focal adhesion. Biochem. Biophys. Res. Commun. 235, 794-798.

Ory, S., and Gasman, S. (2011). Rho GTPases and exocytosis: what are the molecular links? Semin. Cell Dev. Biol. 22, 27-32.

Pavlov, T. S., Chahdi, A., Ilatovskaya, D. V., Levchenko, V., Vandewalle, A., Pochynyuk, O., Sorokin, A., and Staruschenko, A. (2010). Endothelin-1 inhibits the epithelial $\mathrm{Na}^{+}$channel through $\beta$ Pix-14-3-3/Nedd4-2. J. Am. Soc. Nephrol. 21, 833-843.

Rosenberger, G., and Kutsche, K. (2006). $\alpha$ Pix and $\beta$ Pix and their role in focal adhesion formation. Eur. J. Cell Biol. 85, 265-274.

Schlenker, O., and Rittinger, K. (2009). Structures of dimeric GIT1 and trimeric $\beta$-Pix and implications for GIT-PIX complex assembly. J. Mol. Biol. 386, 280-289.

Staruschenko, A., and Sorokin, A. (2012). Role of $\beta$ Pix in the kidney. Front. Physiol. 3:154. doi: 10.3389/ fphys.2012.00154

Received: 21 June 2012; accepted: 25 June 2012; published online: 20 July 2012.

Citation: Hamilton KL and Pao AC (2012) $\beta$ Pix is a new player in renal physiology. Front. Physio. 3:268. doi: 10.3389/fphys.2012.00268

This article was submitted to Frontiers in Renal and Epithelial Physiology, a specialty of Frontiers in Physiology. Copyright $\odot 2012$ Hamilton and Pao. This is an open-access article distributed under the terms of the Creative Commons Attribution License, which permits use, distribution and reproduction in other forums, provided the original authors and source are credited and subject to any copyright notices concerning any third-party graphics etc. 